\title{
Comparison of the Characteristics of Two Kinds of Tea Seed Oils: Oil-tea Seed Oil and Green-Tea Seed Oil
}

\author{
Xinchu Weng \\ Guangxi Colleages and Universities Key Laboratory of Development and High-value \\ Utilization of Beibu Gulf Seafood Resources, Qinzhou University, 12 Binghai Avenue, \\ Qinzhou, 535011, China \\ E-mail: wxch@staff.shu.edu.cn
}

Zhuoting Yun

School of Life Sciences, Shanghai University, 333 Nanchen Road, Shanghai 200444, China

Tel: 86-13045678885

Chenxiao Zhang

Guangxi Colleges and Universities Key Laboratory of Development and High-value Utilization of Beibu Gulf Seafood Resources, Qinzhou University, 12 Binghai Avenue, Qinzhou 535011, China

Received: December 11, 2017 Accepted: February 28, 2018 Published: March 2, 2018 doi:10.5296/jfs.v7i1.12289

URL: https://doi.org/10.5296/jfs.v7i1.12289

\begin{abstract}
Physicochemical properties, fatty acid composition, antioxidant compounds and oxidative stability of oil-tea seed oil (Camellia oleifera Abel.) and green-tea seed oil (Camellia sinensis O. Ktze.) were investigated. The refractive index, saponification value, iodine value, acid value, peroxide value, unsaponifiables were determined to assess the quality of the oils. The major fatty acids of green-tea seed oil and oil-tea seed oil were oleic acid, linoleic acid and palmitic acid. Green-tea seed oil was typical oleic-linoleic-oil with $52.13 \%$ oleic acid and $24.32 \%$ linoleic acid level, whereas oil-tea seed oil was typical oleic-oil with very high oleic acid level (73.67\%). The amount of total phenols, $\alpha$-tocopherol and $\beta$-carotene of green-tea seed oil were $8.68 \mathrm{mg} / \mathrm{kg}, 160.33 \mathrm{mg} / \mathrm{kg}, 3.20 \mathrm{mg} / \mathrm{kg}$, respectively, whereas they were 17.90
\end{abstract}


$\mathrm{mg} / \mathrm{kg}, 85.66 \mathrm{mg} / \mathrm{kg}, 1.18 \mathrm{mg} / \mathrm{kg}$ in oil-tea seed oil, respectively. Green-tea seed oil contained high amounts of $\alpha$-tocopherol which was nearly twice that of oil-tea seed oil. The initial induction period (IP) values of green-tea seed oil and oil-tea seed oil were $6.55 \mathrm{~h}$ and $6.08 \mathrm{~h}$ at $110{ }^{\circ} \mathrm{C}$ by OSI method, respectively, which shows the oxidative stability of two kinds of tea seed oils were preferable. Therefore, oil-tea seed oil could be a good dietary supplement with high level of monounsaturated fatty acids and similar fatty acid composition of olive oil. Green-tea seed oil was a new oil resource which is rich in $\alpha$-tocopherol in China.

Keywords: Oil-tea seed oil, Green-tea seed oil, Fatty acid composition, Antioxidant compounds, Oxidative stability

\section{Introduction}

Oil-tea seed oil and green-tea oil are extracted from the seeds of Theaceae family plants which can produce large quantity of oily seeds (Ravichandran \& Dhandapani, 1992). Oil-tea seeds have been utilized in China for more than 1000 years (Ruter, 2002). Oil-tea trees produce seeds which contain high percentage of oil, but cannot produce tea. Oil-tea seed oil is a special woody lipid and widely used as edible oil in some areas for centuries in China and is one of the main cooking oils in southern central provinces of China, especially Hunan. China is the largest producer of oil-tea seed in the world (Mondal et al., 2004). Today, some Asian countries, such as Korea, Iran, India, Vietnam, Japan etc., also use tea seed oil as important cooking oil. But the area and population of using oil-tea seed oil as edible oil is quite small compared to other vegetable oils in the world. Oil-tea seed oil has high industrial value. Besides edible oil product, it is used to produce soap, margarine, hair oil and other cosmetics (Ruter, 2002)

China has thousands of years' history of planting green-tea trees (Camellia sinensis O. Ktze) which are cultivated mainly for tea production and green-tea seed oil is the by-product. Annual yield of green-tea seed is about 450 million $\mathrm{kg}$ in China (Fan, 1993). Oil content of a whole green-tea seed is in range of $20 \%-25 \%$. But most tea farmers just focus on the tea production and ignore its seed oil production. Sometimes green-tea seeds are mixed with oil-tea seeds, but most of the tea seeds have been collected and are rotted on tea garden. Green-tea seed oil is healthy for human as edible oil (Chen et al., 2003). Considering the large yield annually in China, green-tea seeds are worth to collect to produce oil.

Nevertheless, there is little knowledge of their antioxidant compounds and oxidative stability. As far as we know, there is no research to analyze and compare antioxidant compounds and oxidative stability of these two kinds of oils. These parameters are important to evaluate the quality and utility of the oils.

\section{Materials and Methods}

\subsection{Materials and Chemicals}

The sample of oil-tea seeds and green-tea seeds were obtained from a country farm (Yueyang, Hunan, China). The tea seeds were sealed in plastic bags, and stored at $4{ }^{\circ} \mathrm{C}$ until used. Reagents used for HPLC was purchased from Merck (Darmstadt, Germany). Other reagents used in this study were of analytical grade and purchased from the China National Medicines Co. Ltd. (Shanghai, China). Fatty acid standards were purchased from Nu-Chekprep (USA). Standards used for vitamin E, $\beta$-carotene and 2 N Folin-Ciocalteau Reagent were purchased 


\section{MInstitute ${ }^{\text {Mink }}$}

from Sigma Chemical Co. (St. Louis, MO, USA). All treatments and analyses were performed in at least duplicate.

\subsection{Preparation of Tea Seed Oils}

Tea seeds were finely ground. The oil were extracted by Soxhlet method with petroleum ether (bp range $30-60{ }^{\circ} \mathrm{C}$ ) for $6 \mathrm{~h}$ (Sahari et al., 2004). The ratio of tea seed powder to solvent used was 1:8. The oils were then recovered by evaporating off the solvent using a rotary evaporator and residual solvent was removed by flushing with $99.9 \%$ nitrogen. All oil samples were stored in dark brown glass bottles at $4{ }^{\circ} \mathrm{C}$ until analyzed.

\subsection{Determination of Physico-chemical Properties of Tea Seed Oils}

Official methods (AOAC, 1997) were used for the determination of the reflective index (method Cc 7-25), acid value (method Cd 3d-63), peroxide value (method $\mathrm{Cd} 8 \mathrm{~b}-90$ ), iodine value (method $\mathrm{Cd} 1-25)$, saponification value (method $\mathrm{Cd} 3-25)$ and unsaponifiables (method Ca $6 \mathrm{a}-40)$ of oils.

\subsection{Determination of Fatty Acid Composition}

For the preparation of fatty acid methyl esters (FAME), the AOAC method was modified according to Lee et al. (1998). $100 \mathrm{Mg}$ oil sample was accurately weighed into a stoppered-glass centrifuge vial. $5.0 \mathrm{Ml}$ of hexane was added into the vial, followed by $0.1 \mathrm{ml}$ of $2 \mathrm{~N}$ methanolic $\mathrm{KOH}$. The vial was shaken well for $30 \mathrm{~s}$ and then centrifuged, the upper layer was removed as FAME sample and stored at $-20{ }^{\circ} \mathrm{C}$ until used.

Fatty acid profile was analyzed by a gas chromatograph (GC 7890F, TECHCOMP Co., Shanghai, China) equipped with a flame ionisation detector (FID) (Wang et al., 2006). FAMEs were performed with GC on a Agilent DB-23 capillary column $(60 \mathrm{~m} \times 0.25 \mathrm{~mm}$ $\mathrm{ID} \times 0.25 \mu \mathrm{m}$ film). The column temperature was programmed at $160{ }^{\circ} \mathrm{C}$ for $5 \mathrm{~min}$, then increased to $230{ }^{\circ} \mathrm{C}$ at $2{ }^{\circ} \mathrm{C} / \mathrm{min}$ with a final isothermal period of $10 \mathrm{~min}$. Nitrogen was used as carrier gas with constant flow at $1 \mathrm{ml} / \mathrm{min}$. The injector temperature was set at $250{ }^{\circ} \mathrm{C}$, with a split ratio of 1:30. Flame ionization detector temperature was $280{ }^{\circ} \mathrm{C}$.

\subsection{Determination of Phenols}

Total water-soluble phenols of two kinds of tea seed oils were extracted according to a previous method (Zhong et al., 2007). Total phenol samples were analyzed by Folin-Ciocalteau Method (Singleton et al., 1999). 1 Ml sample was added to a volumetric flask $(10 \mathrm{ml})$ and then added $0.5 \mathrm{ml}$ Folin-Ciocalteu reagent. The solution was shaken and left to stand for $5 \mathrm{~min}$ prior to addition of $2 \mathrm{ml}$ saturated (ca.15\%) sodium carbonate solution and diluted to volume with water. After $1 \mathrm{~h}$, absorbance at $760 \mathrm{~nm}$ against a reagent blank was measured using a UV-2102 spectrophotometer (Unico, Shanghai, China). Calibration was performed using gallic acid and a calibration curve was obtained $\left(y=0.0155 x+0.0013 ; \mathrm{R}^{2}=\right.$ 0.991).

\subsection{Determination of $\alpha$-tocopherol and $\beta$-carotene}

The sample of tea seed oil was prepared according to procedure reported by Gimeno et al. (2000). $\alpha$-Tocopherol and $\beta$-carotene were determined by high-performance liquid chromatography ( 1100 series, Agilent Technologies, USA )with a UV detector. The chromato- 


\section{MInstitute ${ }^{\text {Macrothink }}$}

graphic system consisted of a Zorbax Eclipse XDB-C18 column. $\alpha$-Tocopherol was performed with a mobile phase of $\mathrm{MeOH}-\mathrm{H}_{2} \mathrm{O}$ (98:2). $\beta$-Carotene was performed with a mobile phase of $\mathrm{AcCN}-\mathrm{CH}_{2} \mathrm{Cl}_{2}-\mathrm{MeOH}$ (7:2:1) (Kim et al., 1990).

\subsection{Determination of Oxidative Stability}

The oxidative stability of each sample was determined as the induction period (IP, hours) recorded by a Oxidative Stability Instrument OSI-24 (Omnion, USA), using $5 \mathrm{~g}$ of oil sample heated at $110{ }^{\circ} \mathrm{C}$ with an air flow of $20 \mathrm{~L} / \mathrm{h}$.

\section{Results and Discussion}

\subsection{Crude Oil Yields of Green-tea Seed and Oil-Tea Seed}

The oil yield of oil-tea seed kernel was $41.43 \%$ (Table 1), which agrees with the report data (40-50\%) by Runter (2002). The difference of oil yields were due to the origin of seeds, growth condition and extraction method.

The oil yield of green-tea seed kernel was 31.09\% (Table 1), which suggested that the total yield of green-tea seed oil in China could reach 15 million tons annually from 80 million tons green-tea seed. It is a considerable new vegetable oil resource in China.

Table 1. The physicochemical properties of green-tea seed oil and oil-tea seed oil ${ }^{\mathrm{a}}$

\begin{tabular}{lll}
\hline Parameter & Green-tea seed oil & oil-tea seed oil \\
\hline Yield $(\%, \mathrm{w} / \mathrm{w})$ & $31.09 \pm 0.25$ & $41.43 \pm 0.63$ \\
Physical state at room temperature & Liquid & Liquid \\
Refractive index $\left(20^{\circ} \mathrm{C}\right)$ & $1.4648 \pm 0.0004$ & $1.4676 \pm 0.0005$ \\
Acid value $(\mathrm{mg} \mathrm{KOH} / \mathrm{g})$ & $1.99 \pm 0.01$ & $1.29 \pm 0.12$ \\
Peroxide value $(\mathrm{meq} / \mathrm{kg})$ & $0.84 \pm 0.02$ & $1.91 \pm 0.05$ \\
Saponification value $(\mathrm{mg} \mathrm{KOH} / \mathrm{g})$ & $189.75 \pm 0.57$ & $180.47 \pm 0.56$ \\
Iodine value $(\mathrm{g} \mathrm{I} / 100 \mathrm{~g})$ & $88.54 \pm 0.37$ & $81.54 \pm 0.38$ \\
Unsaponifiables $(\%)$ & $0.80 \pm 0.01$ & $0.65 \pm 0.01$ \\
\hline
\end{tabular}

a: Results are given as mean $\pm \mathrm{SD}, \mathrm{n}=3$.

\subsection{Physicochemical Properties of Green-tea Seed Oil and Oil-tea Seed Oil}

Table 1 shows that green-tea seed oil and oil-tea seed oil were liquid at room temperature. The refractive index of green-tea seed oil and oil-tea seed oil were 1.4648 and 1.4676, respectively. The iodine values of green-tea seed oil is $88.54 \mathrm{gI}_{2} / 100 \mathrm{~g}$ and oil-tea seed oil is $81.54 \mathrm{gI}_{2} / 100 \mathrm{~g}$, which indicate the level of unsaturation in oils, were similar to iodine value of olive oil $\left(80.28 \mathrm{gI}_{2} / 100 \mathrm{~g}\right)$ reported by Aksoy et al. (1988). The saponification values of two kinds of tea seed oils were in range of common vegetable oils such as peanut oil (187-196 mg KOH/g), rapeseed oil (168-181 mg KOH/g), soybean oil (188-195 mg KOH/g) (Zhang, 1999). The saponification value of green-tea seed oil in this study shows that it has high potential for use in the production of liquid soap and shampoos. This result is in agreement with that described in pumpkin seed oil (185.3 $\mathrm{mg} \mathrm{KOH} / \mathrm{g}$ ) (Nyam et al., 2009) and olive oil (181.40-190.45 mg KOH/g) (Méndez \& Falqué, 2007). Peroxide value and acid value have been frequently used as two of the most important parameters to monitor the 


\section{Al Macrothink}

quality of edible oils. These values will provide the much needed information for further refining process of crude seed oils. The low acid value and peroxide value suggest that two kinds of oils are fresh and have high quality (Ojeh, 1981). Unsaponifiables, which contains bioactive compounds like phytosterols and the fat soluble vitamins, have usually quite low percentage in vegetable oils. Unsaponifiable content of green-tea seed oil was higher than that of oil-tea seed oil. This result is in agreement with content of $\alpha$-tocopherol and $\beta$-carotene in the two kinds of oils.

\subsection{Fatty Acid Composition of Two Kinds of Tea Seed Oils}

Fatty acid (FA) compositions are useful for evaluating product quality and authenticity. FA composition may be influenced not only by species or strain, but also by geography, climate, degree of ripeness, harvesting and processing conditions (Lee et al., 1998). The FA compositions of green-tea seed oil and oil-tea seed oil are presented in Table 2. The result shows that green-tea seed oil investigated in this research contained thirteen fatty acids while oil-tea seed oil contained nine fatty acids. Both two oils had high amounts of total unsaturated fatty acids, $78.67 \%$ and $87.17 \%$, respectively (consisted mainly of oleic and linoleic acids, Table 2).

Table 2. The fatty acid composition of two kinds of tea seed oils ${ }^{\mathrm{a}}$

\begin{tabular}{lll}
\hline \multirow{2}{*}{ Fatty acids } & \multicolumn{2}{l}{ Relative content $(\%)$ and ratio } \\
\cline { 2 - 3 } C14:0 & $0.09 \pm 0.01$ & Oil-tea seed oil \\
C16:0 & $17.36 \pm 0.32$ & $0.04 \pm 0.01$ \\
C16:1-9c & $0.11 \pm 0.03$ & $10.63 \pm 0.26$ \\
C18:0 & $3.25 \pm 0.29$ & $0.14 \pm 0.03$ \\
C18:1-9c & $52.13 \pm 1.35$ & $1.83 \pm 0.15$ \\
C18:1-11c & $1.18 \pm 0.18$ & $73.67 \pm 1.54$ \\
C18:2-9c,12c & $24.32 \pm 0.47$ & $1.54 \pm 0.13$ \\
C18:3-6c,9c,12c & $0.02 \pm 0.00$ & $11.09 \pm 0.67$ \\
C18:3-9c, $12 c, 15 c$ & $0.21 \pm 0.04$ & - \\
C20:0 & $0.09 \pm 0.01$ & $0.30 \pm 0.06$ \\
C20:1-11cis & $0.70 \pm 0.16$ & - \\
C22:0 & $0.01 \pm 0.00$ & $0.43 \pm 0.07$ \\
C24:0 & $0.07 \pm 0.02$ & - \\
SFA & $20.86 \pm 0.62$ & - \\
UFA & $78.67 \pm 1.87$ & $12.50 \pm 0.47$ \\
MUFA & $54.12 \pm 1.38$ & $87.17 \pm 2.10$ \\
PUFA & $24.55 \pm 0.50$ & $75.78 \pm 1.76$ \\
SFA/UFA & 0.26 & $11.39 \pm 0.70$ \\
MUFA/PUFA & 2.20 & 0.14 \\
\hline SFA: & & 6.65 \\
\hline
\end{tabular}

SFA: total saturated fatty acids; UFA: total unsaturated fatty acids;

MUFA: monounsaturated fatty acids; PUFA: polyunsaturated fatty acids

a: Results are given as mean $\pm \mathrm{SD}, \mathrm{n}=3$. 


\section{MInstitute ${ }^{\text {Mink }}$}

The dominant fatty acid in green-tea seed oil was oleic acid (52.13\%), followed by linoleic acid $(24.32 \%)$, palmitic acid (17.36\%) and stearic acid (3.25\%). This result of green-tea seed oil is in agreement with those oils reported by Sahari et al. (2004). The high content $(78.67 \%)$ of unsaturated fatty acids (UFA) and abundance of oleic and linoleic acids in green-tea seed oil make it possible to be used as edible cooking oil and salad oil. The high percentage of oleic acid in the oil makes it desirable in terms of nutrition and high stability of cooking and frying oil. In addition, linoleic acid level of green-tea seed oil was almost twice than that of oil-tea seed oil. This result explains green-tea seed oil had higher iodine value than oil-tea seed oil although it contains obvious higher total UFA (see Table 1). Linoleic acid is an essential fatty acid and plays an important role in the germination process of the seeds, and is indispensable for the healthy growth of human skin (Nehdi, 2011). It can be transformed by the organism into series of long fatty acids chains, which are the precursors of eicosanoids (Nasri et al., 2005). The total saturated fatty acids (SFA) of green-tea seed oil is $20.86 \%$, which makes it a strong resistant to oxidative rancidity (Jayadas and Nair, 2006).

Oleic acid was the dominant fatty acid (73.67\%) in oil-tea seed oil, followed by linoleic acid (11.09\%), palmitic acid (10.63\%) and stearic acid (1.83\%). A striking feature of the oil-tea seed oil was the relatively high level $(75.78 \%)$ of monounsaturated fatty acids (MUFA). Oil-tea seed oil can be regarded as high oleic oil because oleic acid was most abundant and its FA composition shows a extremely similar to olive oil (Lee et al., 1998), which has the highest oleic acid content in common vegetable oils. But oil-tea seed oil has lower level of saturated fatty acids than olive oil. Many studies show that olive oil improves coronary health because it is rich in oleic acid (López- Miranda et al., 2010; Bermudez, 2011). Oleic acid can be changed by organism into a set of compounds close to prostaglandins which have important roles at the vessel level and for blood coagulation, so it has fundamental role in cardiovascular diseases prevention (Nehdi et al., 2010). But olive oil is only produced in Mediterranean Sea areas, such as Italy, Spain and is too expensive for general use and world supplies of olive oil were insufficient to meet the demand for healthy oil, thus the oil-tea seed oil may meet the need of high oleic acid inadequate and be a good substitute for olive oil.

The relative ratios of SFA to UFA of green-tea seed oil and oil-tea seed oil were 0.27 and 0.14, respectively. It is a useful index for distinguishing green-tea seed oil from oil-tea seed oil (Lee et al., 1998). MUFA/PUFA (the ratio of monounsaturated fatty acids to polyunsaturated fatty acids) was an important index in edible oil. That of green-tea seed oil and oil-tea seed oil was 2.20 and 6.65, respectively. Some researchers reported that the ratio of diet related to lipid metabolism and liver lipid concentration in vivo (Chang \& Huang, 1998, 1999).

\subsection{Antioxidant Compounds: Phenols, $\alpha$-tocopherol and $\beta$-carotene of Two Kinds of Tea Seed Oils}

The levels of antioxidant compounds in vegetable oil products are important for product stability. The content of antioxidant compounds (total phenols, $\alpha$-tocopherol and $\beta$-carotene) of the two kinds of tea seed oils were shown in Table 3. 


\section{MInstitute Mach $^{m}$}

Table 3. Content of antioxidant compounds in two kinds of tea seed oils (mg/kg) ${ }^{\mathrm{a}}$

\begin{tabular}{lll}
\hline Compound & Green-tea seed oil & Oil-tea seed oil \\
\hline total phenols & $8.68 \pm 0.35$ & $17.90 \pm 0.42$ \\
$\alpha$-tocopherol & $160.33 \pm 4.03$ & $85.66 \pm 2.92$ \\
$\beta$-carotene & $3.20 \pm 0.11$ & $1.18 \pm 0.05$ \\
\hline
\end{tabular}

a: Results are given as mean \pm standard deviation, $\mathrm{n}=5$.

Phenols have been shown to play important roles as antioxidants and influence the flavor of oils. There are few papers about the total water-soluble phenol contents in these two oils. Total phenol content of oil-tea seed oil $(17.90 \mathrm{mg} / \mathrm{kg})$ was higher than the result reported by Zhong et al. (2007), which reported the phenol content of oil-tea seed oil was $4.1 \mathrm{mg} / \mathrm{kg}$ for refined and $11.9 \mathrm{mg} / \mathrm{kg}$ for cold-pressed. As compared to in the results of selected oil (Zhong et al., 2007), total phenol content of green tea seed oil $(8.68 \mathrm{mg} / \mathrm{kg})$ was higher than refined soybean oil (4.2 mg/kg) but lower than cold-pressed Avocado oil $(11.6 \mathrm{mg} / \mathrm{kg}$ ) and cold-pressed pumpkin seed oil $(15.9 \mathrm{mg} / \mathrm{kg})$. Phenol profiles of the two kinds of tea seed oils should be analyzed deeply.

Tocopherol content in seed oils is extremely important as they are natural lipophilic antioxidants found in vegetable oils (Mohamed et al., 2007). Vitamin E deficiency causes defects in the developing nervous system of children and hemolysis in man (Ramadan et al., 2006). Moreover, tocopherols in vegetable oils are believed to protect polyunsaturated fatty acids (PUFA) from peroxidation. $\alpha$-Tocopherol has the most efficient antioxidant activity among vitamin $\mathrm{E}$ homologue in vivo (Kamal-Eldin \& Appelqvist, 1996). In some oils, $\alpha$-tocopherol is abundant and predominant of tocopherols. Oil-tea seed oil investigated in this study contained $85.66 \mathrm{mg} / \mathrm{kg}$ of $\alpha$-tocopherol (Table 3). This result shows that $\alpha$-tocopherol content of oil-tea seed oil was very close to that of olive oil $(85.66 \mathrm{mg} / \mathrm{kg}$ and $85.3 \mathrm{mg} / \mathrm{kg})$ reported before (Gimeno et al., 2000) (Cerchiara et al., 2010). $\alpha$-Tocopherol content of green-tea seed oil investigated in this study was $160.33 \mathrm{mg} / \mathrm{kg}$ (Table 3), which indicated green tea seed oil was a more reasonable resource of $\alpha$-tocopherol than oil-tea seed oil. The level of $\alpha$-tocopherol in green tea seed oil was even higher than that of pumpkin seed oil (151.9 mg/100 g) (Nyam et al., 2009). The result provides useful information for the industrial application of the two tea seed oils. Levels of $\alpha$-tocopherol detected in two tea seed oils may contribute to protect the oil against oxidation.

$\beta$-carotene is the most important precursor for vitamin A (De Leenheer et al., 1988). Both $\beta$-carotene and $\alpha$-tocopherol are involved in the oxidative stability of the oil and have a protective role against cancer and cardiovascular diseases (Gimeno et al., 2000). $\beta$-carotene is believed to prevention of cancer caused by free radicals (Nonomura, 1987). The concentration of $\beta$-carotene in vegetable oils is at a relatively low level compared to $\alpha$-tocopherol. In this investigation, it was found that green tea seed oil contained $3.20 \mathrm{mg} / \mathrm{kg}$ of $\beta$-carotene, which was much higher than oil-tea seed oil $(1.18 \mathrm{~kg} / \mathrm{mg})$. $\beta$-Carotene content of green tea seed oil was also higher than olive oil $(1.58-2.84 \mathrm{mg} / \mathrm{kg})$ reported by Gimeno et al.(2002). This result implies that green tea seed oil may be more stable in storage than oil-tea seed oil as the former is richer in $\beta$-carotene. 


\subsection{Influence of Storage Time on Oxidative Stability}

To get a complete picture of oxidative stability, the induction period (IP, hours) of oils, with different storage time (initial, 1, 2, 3, 4 weeks after extracted) was measured by OSI apparatus (Table 4). The results show that IP values decreased in accord with the increase of storage time.

Table 4. Influence of storage times on $\mathrm{IP}^{\mathrm{a}}$

\begin{tabular}{lll}
\hline Storage time(week) & IP $(\mathrm{h})$ & \\
\cline { 2 - 3 } & Green-tea seed oil & Oil-tea seed oil \\
\hline Initial & $6.55 \pm 0.05$ & $6.08 \pm 0.08$ \\
1 & $6.42 \pm 0.03$ & $5.40 \pm 0.05$ \\
2 & $4.85 \pm 0.05$ & $5.28 \pm 0.03$ \\
3 & $4.67 \pm 0.03$ & $4.82 \pm 0.03$ \\
4 & $4.38 \pm 0.03$ & $4.63 \pm 0.06$ \\
\hline
\end{tabular}

a: All samples were stored at $4^{\circ} \mathrm{C}$ in dark glasses; results are given as mean \pm standard deviation, $\mathrm{n}=3$.

The initial IP values of green-tea seed oil and oil-tea seed oil are $6.55 \mathrm{~h}$ and $6.08 \mathrm{~h}$ at $110{ }^{\circ} \mathrm{C}$, respectively. The results indicated the green-tea seed oil has higher oxidative stability than oil-tea seed oil initially. The unsaturation degree of oil has impact on its oxidative stability. Oxidative stability decreases when PUFA percentages are high and increases when percentages of SFA and MUFA are high (Liu \& White, 1992). The autoxidation speed of linoleic acid is 8 times as that of oleic acid reported by Cao and Weng (1995). As shown in Table 2, green-tea seed oil had higher linoleic acid content than oil-tea seed oil, however its IP value was still higher than oil-tea seed oil. It is well known that the oxidative stability was affected by some minor compounds such as phenols and tocopherols (Velasco \& Dobarganes, 2002). This result might be due to the level of antioxidant compounds in green-tea seed oil, such as $\alpha$-tocopherol nearly twice as that of oil-tea seed oil (Table 3 ).

After stored for 1 week, IP value of oil-tea seed oil was decreased from $6.08 \mathrm{~h}$ to $5.40 \mathrm{~h}$, while IP of green-tea seed oil value just decreased from $6.55 \mathrm{~h}$ to $6.40 \mathrm{~h}$ (Table 4 ). Green tea seed oil was relatively stable during 1 week storage. During first week storage, the antioxidant compound, $\alpha$-tocopherol may still play an important role to oil oxidative stability (Velasco \& Dobarganes, 2002). But after 2 weeks storage, IP value of oil-tea seed oil was 5.28h while green-tea seed oil was just $4.85 \mathrm{~h}$ (Table 4). When oils stored for 3 and 4 weeks, IP values of oil-tea seed oil were a little higher than green tea seed oil. The results suggest that stored more than 2 weeks, oil-tea seed oil were more stable than green-tea seed oil. This trend is explained by the loss of natural antioxidant (tocopherols). Then, oil-tea seed oil with high content of MUFA would be more stable than green tea seed oil with high content of PUFA. Phenol content was not found related to oxidative stability of the oils, the previous research results in our laboratory demonstrated that tyrosol does not show any antioxidant activity during autoxidation of oils (Weng et al., 2017). According to the report by Li (2007), antioxidant activity of phenols is relative to its structure. These results may be ascribed to 


\section{MInstitute ${ }^{\text {Macrothink }}$}

antioxidant activity not only depend on total phenolic content but also type of the phenolic compounds present (Tovar et al., 2001).

\section{Conclusion}

The study demonstrated that the fatty acid composition of oil-tea seed oil is similar to olive oil. The oil contains extremely high oleic acid content with its low SFA level. It suggests that it is nutritional and may be marketed as a dietary supplement with MUFA. The oil has good oxidant stability for long storage. Green-tea seeds give a considerable yield of oil and the oil seems to be a good source of lipid-soluble bioactive compounds. The unique fatty acid profile, high oleic and linoleic acid content makes the oil nutritionally valuable. High content of $\alpha$-tocopherol and $\beta$-carotene makes green tea seed oil has high protection against oxidative stress, relatively long shelf life. The potential for production of oil as a by-product of green tea seed appears to be excellent. The desirable physicochemical characteristics indicate potential uses of both oils in food, pharmaceutics, cosmetics, and other nonfood industries. Oil-tea seed oil is common and good edible oil instead olive oil in China. Considering the large yield of green-tea seed annually, the production of oil from green-tea seed provides the use of renewable resource, and at the same time adding value to this agricultural product.

Nowadays, oil-tea seed oil becomes more and more popular in China, because it is regarded to be good for blood vessels. However, green-tea seed oil is also health oil for human. Some researchers have reported that green-tea seed oil and oil-tea seed oil can prevent cardiovascular disease, lower the blood pressure, reduce body weight but also have the special function of cancer prevention (Zhang \& Zhou, 1995; Lee \& Yen, 2006; Miura et al., 2007; Zhang, 2007; Kim et al., 2008). Green-tea seed oil will become important oil if it is fully investigated and developed.

\section{References}

Aksoy, H., Kahraman, I., Karaosmanoglu, F., \& Civelekoglu, H. (1988). Evaluation of Turkish sulphur olive oil as an alternative diesel fuel. Journal of the American Oil Chemists' Society, 65, 936-938. https://doi.org/10.1007/BF02544514

Bermudez, B. L., Sergio, O., Almudena, M. V., Lourdes, M. P., Yolanda, A., Rocio, J. G., \& Muriana, F. (2011). Oleic Acid in Olive Oil: From a Metabolic Framework Toward a Clinical Perspective. Current Pharmaceutical Design, 17, 831-843. https://doi.org/10.2174/138161211795428957

Cao, G. F., \& Weng, X. C. (1995). Studies on oxidative stability of fish oil (in Chinese). China Oils and Fats, 20, 44-46.

Cerchiara, T., Chidichimo, G., Ragusa, M. I., Belsito, E. L., Liguori, A., \& Arioli, A. (2010). Characterization and utilization of Spanish Broom (Spartium junceum L.) seed oil. Industrial Crops and Products, 31, 423-426. https://doi.org/10.1016/j.indcrop.2009.11.003

Chang, N. W., \& Huang, P. C. (1998). Effects of the ratio of polyunsaturated and monounsaturated fatty acid to saturated fatty acid on rat plasma and liver lipid concentrations. Lipids, 33, 481-487. https://doi.org/10.1007/s11745-998-0231-9

Chang, N. W., \& Huang, P. C. (1999). Comparative effects of polyunsaturated- to saturated fatty acid ratio versus polyunsaturated- and monounsaturated fatty acids to saturated fatty acid ratio on lipid metabolism in rats. Atherosclerosis, 142, 185-191. 


\section{$\triangle$ Macrothink}

https://doi.org/10.1016/S0021-9150(98)00236-6

Chen, F., Wang, X., \& Chen, J. C. S. (2003). Composition and Sensory Evaluation of Tea Seed Oil. the 94th AOCS Annual Meeting and Expo, Kansas City, Missouri.

De Leenheer, A. P., Nelis, H. J., Lambert, W. E., \& Bauwens, R. M. (1988). Chromatography of fat-soluble vitamins in clinical chemistry. $J$ Chromatogr, 429, 3-58. https://doi.org/10.1016/S0378-4347(00)83866-9

Fan, D. Z. (1993). A summary of tea comprehensive utilization (In Chinese). Guangzhou Tea, $2,1-4$.

Gimeno, E., Calero, E., Castellote, A., Lamuela-Raventos, R. M., de la Torre, M. C., \& Lopez-Sabater, M. C. (2000). Simultaneous determination of alpha-tocopherol and beta-carotene in olive oil by reversed-phase high-performance liquid chromatography. $J$ Chromatogr, A 881, 255-259. https://doi.org/10.1016/S0021-9673(00)00219-3

Gimeno, E., Castellote, A. I., Lamuela-Raventós, R. M., De la Torre, M. C., \& López-Sabater, M. C. (2002). The effects of harvest and extraction methods on the antioxidant content (phenolics, [alpha]-tocopherol, and [beta]-carotene) in virgin olive oil. Food Chem, 78, 207-211. https://doi.org/10.1016/S0308-8146(01)00399-5

Jayadas, N. H., \& Nair, K. P. (2006). Coconut oil as base oil for industrial lubricants--evaluation and modification of thermal, oxidative and low temperature properties. Tribology International, 39, 873-878. https://doi.org/10.1016/j.triboint.2005.06.006

Kamal-Eldin, A., \& Appelqvist, L.-Å. (1996). The chemistry and antioxidant properties of tocopherols and tocotrienols. Lipids, 31, 671-701. https://doi.org/10.1007/BF02522884

Kim, N. H. et al. (2008). Green tea seed oil reduces weight gain in C57BL/6J mice and influences adipocyte differentiation by suppressing peroxisome proliferator-activated receptor-gamma. Pflugers Arch, 457, 293-302. https://doi.org/10.1007/s00424-008-0537-y

Kim, Y., English, C., Reich, P., Gerber, L. E., \& Simpson, K. L. (1990). Vitamin A and carotenoids in human milk. Journal of Agricultural and Food Chemistry, 38, 1930-1933. https://doi.org/10.1021/jf00100a011

López-Miranda, et al. (2010). Olive oil and health: Summary of the II international conference on olive oil and health consensus report, Jaén and Córdoba (Spain) 2008. Nutrition, metabolism, and cardiovascular diseases: NMCD, 20, 284-294. https://doi.org/10.1016/j.numecd.2009.12.007

Lee, C. P., \& Yen, G. C. (2006). Antioxidant activity and bioactive compounds of tea seed (Camellia oleifera Abel.) oil. J Agric Food Chem, 54, 779-784. https://doi.org/10.1021/jf052325a

Lee, D. S., Noh, B. S., Bae, S. Y., \& Kim, K. (1998). Characterization of fatty acids composition in vegetable oils by gas chromatography and chemometrics. Anal Chim Acta, 358, 163-175. https://doi.org/10.1016/S0003-2670(97)00574-6

Li, J. X., Li, J. Y., \& Weng, X. C. (2007). Magnolol Derivatives:Synthesis and Antioxidation Activity Examination. Journal of the Chinese Cereals and OilsAssociation, 22, 71-74.

Liu, H.-R., \& White, P. (1992). Oxidative stability of soybean oils with altered fatty acid compositions. Journal of the American Oil Chemists' Society, 69, 528-532. 
https://doi.org/10.1007/BF02636103

Méndez, A. I., \& Falqué, E. (2007). Effect of storage time and container type on the quality of extra-virgin olive oil. Food Control, 18, 521-529. https://doi.org/10.1016/j.foodcont.2005.12.012

Miura, D., Kida, Y., \& Nojima, H. (2007). Camellia oil and its distillate fractions effectively inhibit the spontaneous metastasis of mouse melanoma BL6 cells. FEBS Lett, 581, 2541-2548. https://doi.org/10.1016/j.febslet.2007.04.080

Mohamed, R., Fernández, J., Pineda, M., \& Aguilar, M. (2007). Roselle (Hibiscus sabdariffa) Seed Oil Is a Rich Source of $\gamma$-Tocopherol. Journal of Food Science, 72, S207-S211. https://doi.org/10.1111/j.1750-3841.2007.00285.x

Mondal, T. K., Bhattacharya, A., Laxmikumaran, M., \& Ahuja, P. S. (2004). Recent advances of tea (Camellia sinensis) biotechnology. Plant Cell Tiss Org, 76, 195-254. https://doi.org/10.1023/B:TICU.0000009254.87882.71

Nasri, N., Khaldi, A., Fady, B., \& Triki, S. (2005). Fatty acids from seeds of Pinus pinea L.: Composition and population profiling. Phytochemistry, 66, 1729-1735. https://doi.org/10.1016/j.phytochem.2005.05.023

Nehdi, I., Omri, S., Khalil, M. I., \& Al-Resayes, S. I. (2010). Characteristics and chemical composition of date palm (Phoenix canariensis) seeds and seed oil. Industrial Crops and Products, 32, 360-365. https://doi.org/10.1016/j.indcrop.2010.05.016

Nehdi, I. A. (2011). Characteristics and composition of Washingtonia filifera (Linden ex André) H. Wendl. seed and seed oil. Food Chem, 126, 197-202. https://doi.org/10.1016/j.foodchem.2010.10.099

Nonomura, M. (1987). Naturally-derived carotene/oil composition San Diego, Calif. Microbio Resources, Inc., US.

Nyam, K. L., Tan, C. P., Lai, O. M., Long, K., \& Che Man, Y. B. (2009). Physicochemical properties and bioactive compounds of selected seed oils. LWT - Food Science and Technology, 42, 1396-1403. https://doi.org/10.1016/j.lwt.2009.03.006

Ojeh, O. A. (1981). Effect of refining on the physical and chemical properties of cashewkernel oil. International Journal of Food Science \& Technology, 16, 513-517. https://doi.org/10.1111/j.1365-2621.1981.tb01844.x

Ramadan, M. F., Sharanabasappa, G., Seetharam, Y. N., Seshagiri, M., \& Moersel, J. T. (2006). Characterisation of fatty acids and bioactive compounds of kachnar (Bauhinia

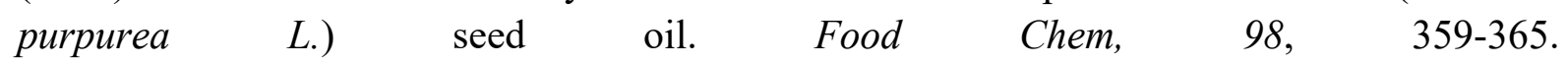
https://doi.org/10.1016/j.foodchem.2005.06.018

Ravichandran, R., \& Dhandapani, M. (1992). Composition, Characteristics and Potential Uses of South Indian Tea Seeds. J Food Sci and Technol, India, 29, 394-396.

Ruter, J. M. (2002). Nursery production of tea oil camellia under different light levels. ASHS Press, Alexandria,VA.

Sahari, M. A., Ataii, D., \& Hamedi, M. (2004). Characteristics of tea seed oil in comparison with sunflower and olive oils and its effect as a natural antioxidant. J Am Oil Chem Soc, 81, 585-588. https://doi.org/10.1007/s11746-006-0945-0 


\section{Macrothink

Singleton, V. L., Orthofer, R., \& Lamuela-Raventos, R. M. (1999). Analysis of total phenols and other oxidation substrates and antioxidants by means of Folin-Ciocalteu Reagent. Methods in Enzymology, 299, 152-178. https://doi.org/10.1016/S0076-6879(99)99017-1

Society, A. O. C. (1997). Official methods and recommended practices of the American Oil Chemists' Society. American Oil Chemists' Society, Champaign, IL.

Tovar, M. J., Motilva, M. J., \& Romero, M. P. (2001). Changes in the phenolic composition of virgin olive oil from young trees (Olea europaea L. cv. Arbequina) grown under linear irrigation strategies. J Agric Food Chem, 49, 5502-5508. https://doi.org/10.1021/jf0102416

Velasco, J., \& Dobarganes, C. (2002). Oxidative stability of virgin olive oil. Eur. J. Lipid Sci. Technol, 104 661-676. https://doi.org/10.1002/1438-9312(200210)104:9/10\%3C661::AID-EJLT661\%3E3.0.CO;2-D

Wang, H. X., Wu, H., Ho, C. T., \& Weng, X. C. (2006). Cocoa butter equivalent from enzymatic interesterification of tea seed oil and fatty acid methyl esters. Food Chem, 97, 661-665. https://doi.org/10.1016/j.foodchem.2005.04.029

Weng, X., Luo, S., \& Song, Y. (2017). Variations of phenols and squalene in EVOOs under different conditions. J Res Anal, 3(1), 24-33.

Zhang, B., \& Zhou, Z. Y. (1995). Effects of tea seed oil and soybean oil on free oxygen radical and activities of antioxidative enzymes in rats (In Chinese). Acta Nutrimenta Sinica, 17, 199-204.

Zhang, C. P. (2007). Study on serum lipid and antiatherosclerosis effect of camellia oil (In Chinese). Chin Hosp Pharm J, 27, 596-598.

Zhang, G. W. (1999). Oil Chemistry. China Financial and economic publishing house, Beijing.

Zhong, H. Y., Bedgood, D. R., Bishop, A. G., Prenzler, P. D., \& Robards, K. (2007). Endogenous biophenol, fatty acid and volatile profiles of selected oils. Food Chem, 100, 1544-1551. https://doi.org/10.1016/j.foodchem.2005.12.039

\section{Copyright Disclaimer}

Copyright for this article is retained by the author(s), with first publication rights granted to the journal.

This is an open-access article distributed under the terms and conditions of the Creative Commons Attribution license (http://creativecommons.org/licenses/by/3.0/). 